\title{
Differing Mechanisms for Glutamate Receptor Aggregation on Dendritic Spines and Shafts in Cultured Hippocampal Neurons
}

\author{
Ruifa Mi, ${ }^{1}$ Xiaopei Tang, ${ }^{1}$ Ralph Sutter, ${ }^{1}$ Desheng Xu, ${ }^{2}$ Paul Worley, ${ }^{2}$ and Richard J. O'Brien ${ }^{1,2}$ \\ Departments of ${ }^{1}$ Neurology and ${ }^{2}$ Neuroscience, Johns Hopkins University School of Medicine, Baltimore, \\ Maryland 21287
}

\begin{abstract}
We have explored the ability of axons from spinal and hippocampal neurons to aggregate NMDA- and AMPA-type glutamate receptors on each other as a way of exploring the molecular differences between their presynaptic elements. Spinal axons, which normally cluster only AMPA-type glutamate receptors on other spinal neurons, cluster both AMPA- and NMDA-type glutamate receptors on the dendritic shafts of hippocampal interneurons but are ineffective at clustering either subtype of glutamate receptor on the dendritic spines of hippocampal pyramidal neurons. Conversely, hippocampal axons appear to be multipotent, capable of clustering both AMPAand NMDA-type glutamate receptors on hippocampal interneurons and pyramidal cells. The secretion of the neuronal activity-
\end{abstract}

regulated pentraxin (Narp) by hippocampal axons is restricted to contacts with interneurons. Exogenous application of Narp to cultured hippocampal neurons results in clusters of both NMDA- and AMPA-type glutamate receptors on hippocampal interneurons but not hippocampal pyramidal neurons. Because Narp displays no ability to directly aggregate NMDA receptors, we propose that Narp aggregates NMDA receptors in hippocampal interneurons indirectly through cytoplasmic coupling to synaptic AMPA receptors. Furthermore, our data suggest the existence of a novel molecule(s), capable of forming excitatory synapses on dendritic spines.

Key words: glutamate receptor; dendritic spine; Narp; AMPA; NMDA; hippocampal neuron
Recently, we have characterized a potential synaptic organizing molecule, neuronal activity-regulated pentraxin (Narp), a secreted $55 \mathrm{kDa}$ protein that is an immediate early gene regulated by synaptic activity (O'Brien et at 1999). Narp is selectively enriched at excitatory synapses on the dendritic shafts of cultured spinal and hippocampal neurons and has the capacity to aggregate AMPA-type glutamate receptors through a direct interaction. Narp does not cluster or immunoprecipitate with NMDA- or kainate-type glutamate receptors. In neurons, the evidence that Narp plays an important role in aggregating AMPA receptors at excitatory synapses is related to the effect of exogenously applied Narp (O'Brien et al., 1999) and to the effect of a series of dominant negative Narp mutants (O'Brien et al., 2002).

One interesting aspect of the Narp hypothesis is that Narp appears only at excitatory synapses that form on dendritic shafts and is not present at excitatory synapses on dendritic spines (O'Brien et al., 1999). Because spine synapses make up the majority of excitatory synapses in the brain (Sheperd, 1998), the role of Narp will be limited to those neurons with excitatory synapses that occur on their dendritic shafts. Such neurons include nearly all spinal neurons (Jakowec et al., 1995; O'Brien et al., 1997) and most hippocampal interneurons (Craig et al., 1994; Acsady et al., 1998). A growing distinction has developed between excitatory synapses that occur on dendritic shafts and those that occur on dendritic spines. These two types of excitatory synapses occur in distinct classes of neurons in a mutually exclu-

Received March 1, 2002; revised May 7, 2002; accepted June 7, 2002.

This work was supported by National Institutes of Health Grant R01-NS37694 and grants from the Christopher Reeve Paralysis Association, The Center for ALS Research at Hopkins, and the Joseph and Esther Klingenstein Foundation.

Correspondence should be addressed to Richard J. O'Brien, Pathology 627A, Johns Hopkins Hospital, 600 North Wolfe Street, Baltimore, MD 21287. E-mail: ro’brien@jhmi.edu.

Copyright (C) 2002 Society for Neuroscience $0270-6474 / 02 / 227606-11 \$ 15.00 / 0$ sive manner (O’Brien et al., 1997; Allison et al., 1998; Rutherford et al., 1998). In the spinal cord, most synapses, both excitatory and inhibitory, occur on dendritic shafts (Jakowec et al., 1995; O'Brien et al., 1997), whereas in the brain and hippocampus most neurons receive excitatory synapses exclusively on dendritic spines (Shepherd, 1998). In addition to differences in morphology, synaptic proteins also appear to be differentially expressed at excitatory spine and shaft synapses (Allison et al., 1998; Gomperts et al., 1998; Lissen at al., 1998; Rao et al., 1998; Liao et al., 1999). Although Narp remains an attractive candidate to regulate glutamate receptors at excitatory shaft synapses, the identity of those molecules that regulate glutamate receptor accumulation at spine synapses is not yet clear. Both the neuroligin/neurexin system (Song et al., 1999) and the EphR/ephrin system (Torres et al., 1998) have been postulated to play a role at spine synapses, although the evidence in support of these claims has been indirect.

By examining synaptic contacts between spinal and hippocampal neurons, we have attempted to examine the degree of shared molecular elements between the two systems. Our data suggest the presence of two distinct, nonoverlapping systems for clustering glutamate receptors at excitatory synapses. Specifically we propose that the molecules that induce glutamate receptor clustering on dendritic shafts differ from those that induce glutamate receptor clusters on the dendritic spines of hippocampal pyramidal neurons. Although spinal neurons contain only Narp-based aggregating systems, hippocampal pyramidal neurons appear to carry both a Narp-based and a non-Narp-based system.

\section{MATERIALS AND METHODS}

Neuronal cultures and transfections. Spinal cord and hippocampal neurons taken from embryonic day (E) 15 and E20, respectively, Sprague Dawley rat embryos were cultured on glass coverslips as described previously at a density of 200,000 cells per $60 \mathrm{~mm}$ dish (O'Brien et al., 1997, 1999, 
2002). Neurons were transfected with plasmid DNA at $72 \mathrm{hr}$ after plating using the calcium-phosphate technique described in Dong et al., (1997). The transfected DNA consisted of $2 \mu \mathrm{g}$ of a green fluorescent protein (GFP)-expressing construct and $6 \mu \mathrm{g}$ of pCMV lacZ (Stratagene) (control), C-terminal myc epitope-tagged Narp (mycNarp), or the dominant negative Narp mutant (NarpN) (O'Brien et al., 2002). In cotransfection experiments, the rate of concordant staining for GFP and any of the myc-tagged constructs at the level of the cell body and proximal dendrite was $>90 \%$. The rate of transfections using these techniques was $\sim 10 \%$. The neurons were trypsinized off the dish using $0.025 \%$ trypsin/EDTA (Invitrogen) 4-5 hr after transfection, and 40,000 transfected neurons were added to the cultures of mature $(10 \mathrm{~d})$ spinal or hippocampal neurons. The cocultures were allowed to proceed for 4 more days. In some cases the postsynaptic spinal neurons were transfected with EYFPNuc (Clontech), a nuclear marker of transfected cells, on day 4 in vitro, before the presynaptic spinal or hippocampal neurons were added.

Motoneurons. Spinal motoneurons were isolated from E15 rat embryos using the immunopanning technique of Camu and Henderson (1992), leaving out the metrizamide step to maximize yield. These cells were grown on glial-coated coverslips as described above. Our yield was usually $\sim 500,000$ cells from $10-15$ cords. Using Islet 1 staining, these cultures were at least $80 \%$ pure. They were transfected, trypsinized, and added to mature hippocampal neurons as described above.

Ephrin A5, ephrin B1, and neurexin 1B. Full-length neurexin 1B was isolated from cultured rat hippocampus via RT-PCR using the primers 5'TATAGCTAGC GCCCCGCCATGTACCAGAGGATGCTCCGGTGCG (forward) and 5'GAGAAA GCTTGACATAATACTCCTTATCCTTGT (reverse). These primers included Hin $\mathrm{d} 3$ and NheI sites facilitating subcloning into pcDNA 3.1(-) myc His. An extracellular hemagglutin (HA) tag was added between amino acid (aa) 61 and 62 .

Full-length ephrin A5 was isolated from cultured hippocampal neurons using the primers 5'TATAGCTAGCTCCGCCGCTGGCTAGGCGTGATGTT (forward) and 5'GAGAAAGCTTCCCTGATGTTTTCTGTGACAGGTGA (reverse). An HA epitope tag (extracellular) was inserted between amino acid 27 and 28 .

Full-length ephrin B1 was isolated from cultured rat hippocampal neurons using the primers 5'TATAAGCAGGCAGCAGTCCATGCGCGGGTTG (forward) and 5'GAGAAAGCTTGCGGCCGCTCAGACCTTGTAGTA (reverse). An extracellular HA tag was inserted between amino acid 38 and 39.

Each clone was fully sequenced, and its surface expression in HEK 293 cells was verified by Western blot, surface biotinylation, and live staining with anti-HA antibodies.

Receptor clustering assay. Cocultures of transfected neurons and mature hippocampal or spinal neurons were fixed in sequential paraformaldehyde and methanol (Liao et al., 1999) and stained with monoclonal antibodies to the AMPA receptor subunit GluR2 (Chemicon) (1:200) or the NMDA receptor subunit NR1 (SC311 $0.5 \mu \mathrm{g} / \mathrm{ml})$. These were followed by a rhodamine anti-mouse antibody (Jackson ImmunoResearch). In other cases we used rabbit polyclonal antibodies to GAD 65 (Chemicon) (1:150), the $\mathrm{GABA}_{\mathrm{A}}$ receptor $\alpha 1$ subunit (Upstate Biotechnology) (1:250), or the AMPA receptor GluR1 subunit (O'Brien et al., 1997) $(2 \mu \mathrm{g} / \mathrm{ml})$. Live staining with a rabbit anti-myc antibody (Covance) $(1: 700 \times 45 \mathrm{~min})$ sometimes preceded fixation to visualize the surface expression of cotransfected mycNarp. In this case the mouse monoclonal NR1 or GluR2 antibodies would be used to label postsynaptic receptor clusters. Using an AMCA-labeled anti-rabbit antibody and a rhodamine-labeled anti-mouse antibody, we could simultaneously visualize axons (green), surface mycNarp (blue), and postsynaptic receptors $(r e d)$. Coverslips were mounted in Prolong (Molecular Probes). After immunostaining and mounting, the identity of the transfected constructs (hippocampal vs spinal or control vs NarpN) was hidden by letter coding and revealed only after the results were tabulated for all the constructs being evaluated in that particular experiment. Experiments were set up so that control- and NarpN-transfected hippocampal neurons and control-transfected spinal neurons were all added to the same batch of mature hippocampal or spinal neurons and run concurrently. A series of four separate transfections/assays using postsynaptic hippocampal neurons and three using postsynaptic spinal neurons were performed. Control experiments involving transfected motoneurons were run separately and were not blinded (see below).

In a blinded fashion, and with a $63 \times$ objective, we identified consecutive postsynaptic hippocampal or spinal neurons that displayed a moderate number of spiny or shaft clusters of NR1 GluR2 or GABA receptors. We deliberately stayed away from hippocampal pyramidal cells or interneurons with dense receptor clusters, to avoid nonspecific associations between the transfected axon and glutamate receptor clusters on the postsynaptic neuron. Despite this, we still sampled $>50 \%$ of the spiny and aspiny populations. A single experiment examining the entire population of postsynaptic neurons showed a similar pattern. Our definition of a spiny synapse is one in which a bright cluster of NMDA or AMPA receptors (usually circular) is separated from, or protruding from, the background immunostaining of the parent dendrite. A shaft synapse is one in which the immunostaining (often rectangular) is contained within the background immunostaining of the parent dendrite. Neurons tend to have the great majority of their clustered GluR1 or NR1 $(>80 \%)$ in one type or the other. In addition, the number of receptor clusters on aspiny postsynaptic neurons was used to distinguish hippocampal interneurons from spinal neurons (see Results). If the selected neuron was not GFP positive (untransfected), the number of GFP-positive "axons" contacting the untransfected cell was determined using the definition for axon detailed in O'Brien et al., $(1999,2002)$. The site of contact between the dendrite of the untransfected cell and the crossing GFP-positive axon was examined at $100 \times$ and scored for the presence of clustered NR1, GluR2, etc. Equivocal cases of colocalization were digitized and superimposed using "Metamorph" (Universal Imaging) software. Our definition of colocalization between an axon and a cluster of immunogen requires that the cluster of immunogen be centered on or be contained within the GFP staining of the axon. In addition, the directionality of the two, if present (i.e., rectangular/elliptical), should be similar unless the cluster of immunogen is contained completely within the GFP-positive axon. We did not attempt to determine whether the clusters were big or small but just whether they were present or absent, and this therefore represents a "forced choice" paradigm. When an axon touched several dendrites on the same untransfected neuron, it was considered positive if any contact resulted in a cluster. Similarly, if a process ran obliquely, it was scored as positive if it was associated with a cluster at any point. We also noted whether the postsynaptic cluster occurred on the dendritic shaft or a protruding spine. A total of 10-13 spiny and 10-13 non-spiny hippocampal neurons satisfying the above criterion were analyzed per coverslip, and each experiment included duplicate coverslips of similarly transfected cells. The mean rate of immunogen clusters per axon-dendrite contact was calculated for each construct in a series of four separate experiments. In practice this means that each point shown in Table 1 is the result of $80-100$ axon-dendrite contacts assayed over three or four separate experiments.

HEK 293 transfections. HEK 293 cells in six-well dishes were transfected with a combination of Narp, HA-tagged GluR1 (aa 25), myctagged NR1 (aa 47), and untagged NR2A (1 $\mu \mathrm{g}$ each). The cells were grown for $48 \mathrm{hr}$ in APV plus CNQX and then stained live with antibodies to Narp (rabbit; red), NR1 (mouse anti-myc; green), and GluR1 (rat anti-HA; blue).

HEK 293-neuron cocultures. HEK 293 cells were transfected with mycNarp or HA-tagged versions of ephrin A5, ephrin B1, or neurexin 1B. Twenty-four hours after transfection, 50,000 of the 293 cells were added to $60 \mathrm{~mm}$ cultures of mature (D14) hippocampal or spinal neurons that had been grown at a density of 200,000 per dish. After an additional $24 \mathrm{hr}$, the epitope-tagged construct was labeled live with mouse or rabbit anti-myc (Narp) or rat anti-HA (ephrin and neurexin) antibodies. The cells were rinsed and fixed with sequential paraformaldehyde and methanol and stained with antibodies to GluR1, GluR2, or NR1. Coverslips were then examined for 293 cells expressing the surface construct of interest, and any overlap with a hippocampal pyramidal neuron or interneuron was examined closely for the presence of colocalized myc (or HA) with NR1, GluR1, or GluR2.

Surface biotinylation and immunoblotting. D14 spinal and hippocampal neurons grown in $60 \mathrm{~mm}$ dishes at a density of 1 million per dish were surface biotinylated as described (Mammen et al., 1997) and streptavidin immunoprecipitated. Total and biotinylated surface proteins were resolved by SDS-PAGE $(25 \mu \mathrm{g}$ per lane $)$, transferred to Immobilon-P (Millipore, Bedford MA), and probed with antibodies to NR1 (Upstate Biotechnology; $0.5 \mu \mathrm{g} / \mathrm{ml}$ ), GluR2 (Chemicon) (1:700), or GluR1 (O’Brien et al., 1997) $(0.5 \mu \mathrm{g} / \mathrm{ml})$. Proteins were visualized with enhanced chemiluminescence (ECL, Amersham).

\section{RESULTS}

\section{Cultured hippocampal neurons display clustered, synaptic glutamate receptors in two different patterns}

By $10 \mathrm{~d}$ in vitro, cultured hippocampal neurons taken from E20 rats can be divided into one of two categories, spiny or aspiny, on 

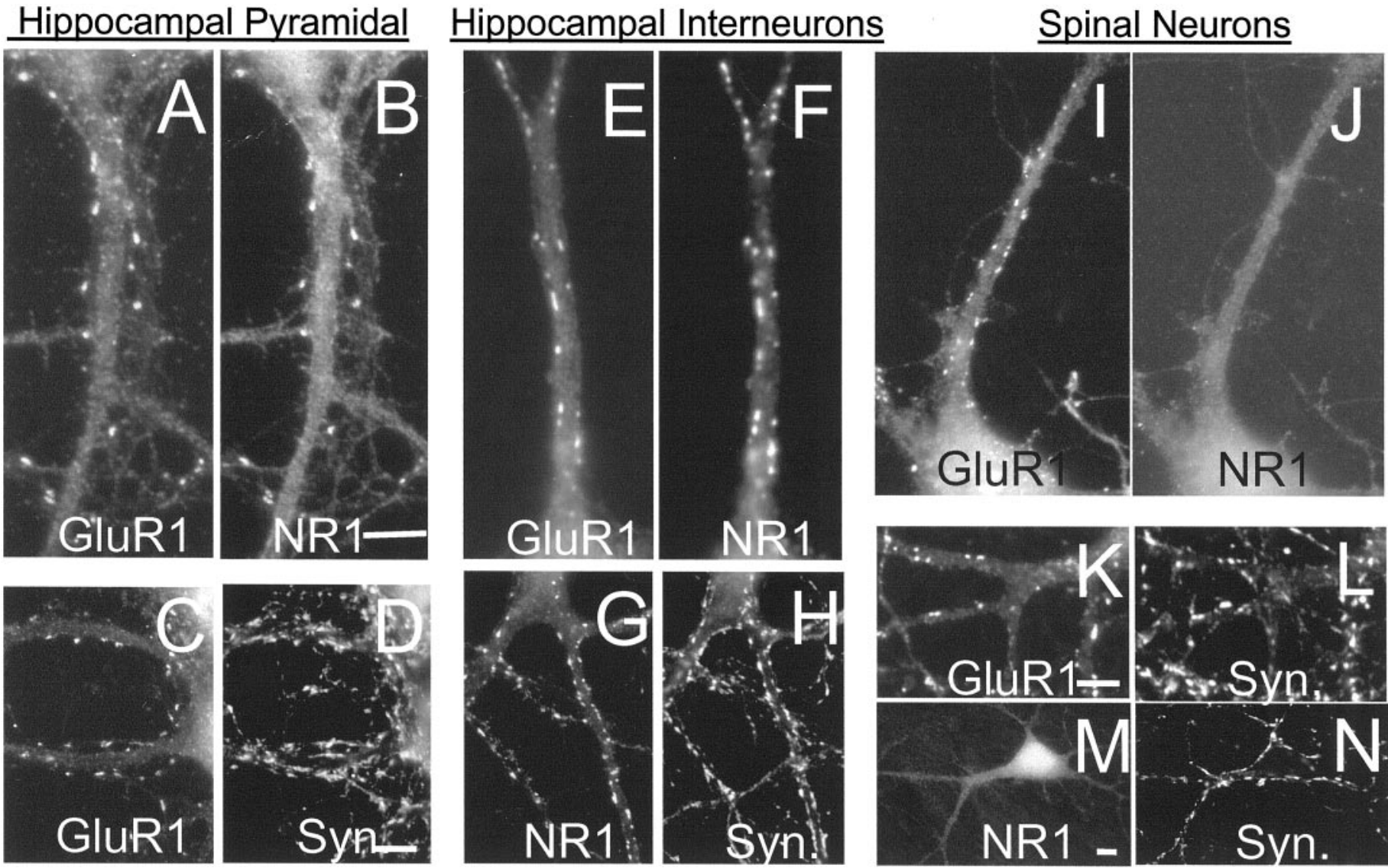

Figure 1. The distribution of glutamate receptors in cultured hippocampal and spinal neurons. Neurons grown for 2 weeks in vitro were fixed and permeabilized as described in Materials and Methods and stained with antibodies to the glutamate receptor subunits GluR1 and NR1 and the presynaptic vesicle protein synaptophysin $(S y n)$. Although NR1 and GluR1 showed close colocalization on the spines $(A, B)$ and shafts $(E, F)$ of hippocampal neurons, there was no colocalization in spinal neurons $(I, J)$. Nearly all clusters of NR1 or GluR1 were associated with synaptophysin. Scale bars, $5 \mu \mathrm{m}$.

the basis of staining for glutamate receptor subunits. Spiny hippocampal neurons (Fig. $1 A-D$ ) comprise nearly $80 \%$ of the neurons in these cultures and have synaptic (synaptophysin associated) glutamate receptor clusters, consisting of both AMPA receptors (GluR1 and GluR2) and NMDA receptors (NR1) almost exclusively on protuberant dendritic spines. The remaining $20 \%$ of the neurons in these cultures are aspiny and have synaptically clustered AMPA and NMDA receptors almost exclusively on their dendritic shafts (Fig. $1 E-H)$. The spiny class of neurons most likely represents excitatory hippocampal pyramidal cells, whereas the aspiny cells are likely to be GABAergic interneurons (Banker and Cowan 1979; Craig et al., 1994; Liao et al., 1999). Our own data using a rabbit anti-GAD 65 antibody (a marker for inhibitory neurons) showed beautiful staining of the cell soma (Golgi/endoplasmic reticulum) in 78 of $86(90 \%)$ aspiny interneurons and 0 of 123 spiny neurons, implying that the morphologic differences do indeed signify a neurochemical difference.

The distribution of glutamate receptor clusters on cultured aspiny hippocampal interneurons is similar to that seen in cultured spinal cord neurons (inhibitory and excitatory) where synaptic glutamate receptor clusters are also arranged exclusively on dendritic shafts (Fig. 1I-N) (O’Brien et al., 1997). One important difference between the distribution of glutamate receptors on spinal neurons and hippocampal interneurons, however, is that the cultured spinal neurons do not have clustered NMDA receptor clusters at their excitatory synapses (Fig. 1, compare $F, G$,
$J-M)$. To avoid conf usion, cultured neurons from the spinal cord will be referred to as "spinal cord neurons," and neurons from the hippocampus, which have dendritic spines after $10 \mathrm{~d}$ in vitro, will be referred to as "spiny hippocampal neurons" or "hippocampal pyramidal cells."

We began our investigation by asking a simple question. Can spinal cord neurons, the axons of which normally cluster glutamate receptors on the dendritic shafts of other spinal neurons, aggregate glutamate receptors on the dendrites of hippocampal pyramidal cells, which normally receive excitatory synapses on dendritic spines? Our assay consisted of transfecting spinal cord neurons after $3 \mathrm{~d}$ in culture with a plasmid encoding GFP to allow visualization of its axons. These cells would comprise the presynaptic neurons. After transfection, the GFP-expressing cells were trypsinized off their dish and added to cultures of mature hippocampal neurons (D10 in vitro), containing both spiny and aspiny cells as described above. These hippocampal neurons would comprise the postsynaptic cells. As a control, we transfected cultured hippocampal neurons (also grown for $3 \mathrm{~d}$ in vitro) with a GFP-expressing plasmid and added them to cultures of mature (D10 in vitro) hippocampal neurons. The heterochronic nature of these cultures was dictated both by the need to distinguish spiny and aspiny neurons in the postsynaptic hippocampal cultures (which takes $\sim 10 \mathrm{~d}$ ) and the need to use young presynaptic neurons to survive the transfection and dissociation process. After transfecting and trypsinization, the presynaptic and 
postsynaptic neurons were cocultured for $4-5 \mathrm{~d}$. Sites of contact between the axons of the transfected spinal/hippocampal neurons and the dendrites of the mature hippocampal neurons were examined closely for the presence of postsynaptic clusters of the glutamate receptor subunits GluR2 and NR1. The definitions of axons and dendrites used in this study mirrors those in our previous publications (O'Brien et al., 1999, 2002). It should be noted that because of the experimental conditions used, there is little risk of confusing any added unlabeled presynaptic neurons with the preexisting mature postsynaptic hippocampal pyramidal neurons, both because the number of added presynaptic neurons was one-fifth the number of postsynaptic cells and because dendritic spines are never seen in the GFP-positive presynaptic hippocampal or spinal neurons (and presumably in their untransfected compatriots) 4-5 d after trypsinization and replating. In addition, the culture conditions allowed us to distinguish mature hippocampal interneurons from added unlabeled spinal neurons because the number of AMPA receptor clusters on the shafts of postsynaptic hippocampal interneurons after 10-14 d in vitro greatly outnumber those on the added presynaptic neurons. We found that 15 postsynaptic AMPA receptor clusters per cell (viewed with a $63 \times$ objective) gave a near $100 \%$ distinction. This latter observation could be confirmed independently by clustered NMDA receptors, which were infrequent or absent on spinal neurons, whereas they were colocalized 1:1 with AMPA receptor clusters on hippocampal interneurons (see below).

\section{The capacity of spinal and hippocampal axons to cluster AMPA-type glutamate receptors differs}

Consecutive, randomly chosen, spine-bearing dendrites from hippocampal pyramidal neurons were identified and examined for contacts with GFP-positive axons from spinal cord or hippocampal neurons. Sites of contact were then examined carefully for the presence of overlapping NR1 or GluR2 clusters, either directly on the dendritic shaft or on an associated dendritic spine. As shown in Figure 2 and Table 1, the axons of transfected hippocampal neurons readily induced clusters of glutamate receptors on contacted spiny hippocampal neurons, nearly always on a protruding dendritic spine (Fig. 2A,B). Quantitatively, 55\% of hippocampal axons were associated with spiny clusters of GluR2, whereas $71 \%$ were associated with spiny clusters of NR1. Although we use the phrase "induce clusters" throughout this paper to describe the action of the presynaptic axon, we understand that we cannot distinguish this possibility from the less likely possibility that the axons are associating with preexisting clusters of glutamate receptors.

When spinal cord neurons were transfected with GFP and added to cultures of mature hippocampal neurons, their axons displayed a much different pattern of receptor clustering ability. As shown in Figure 2C,D and Table 1, spinal cord axons showed a greatly diminished ability to induce clusters of GluR2 on the spines of spiny hippocampal neurons $(24 \%)$ and almost no ability to induce clusters of NR1 (13\%). Moreover, we saw almost no examples of spinal axons associated with clusters of GluR2 or NR1 on the shafts of spiny hippocampal neurons (Fig. $2 C, D$, arrowheads). The association between the axons of spinal cord neurons and clustered GluR2 on the spines of hippocampal neurons, although small, is likely greater than chance, because the incidence of clustered GluR2 on the spines or shafts of hippocampal neurons associated with contacts from axons of a motoneuron-enriched population of spinal cord neurons was significantly lower $(12 \% ; p<0.02)$ (Table 1$)$.
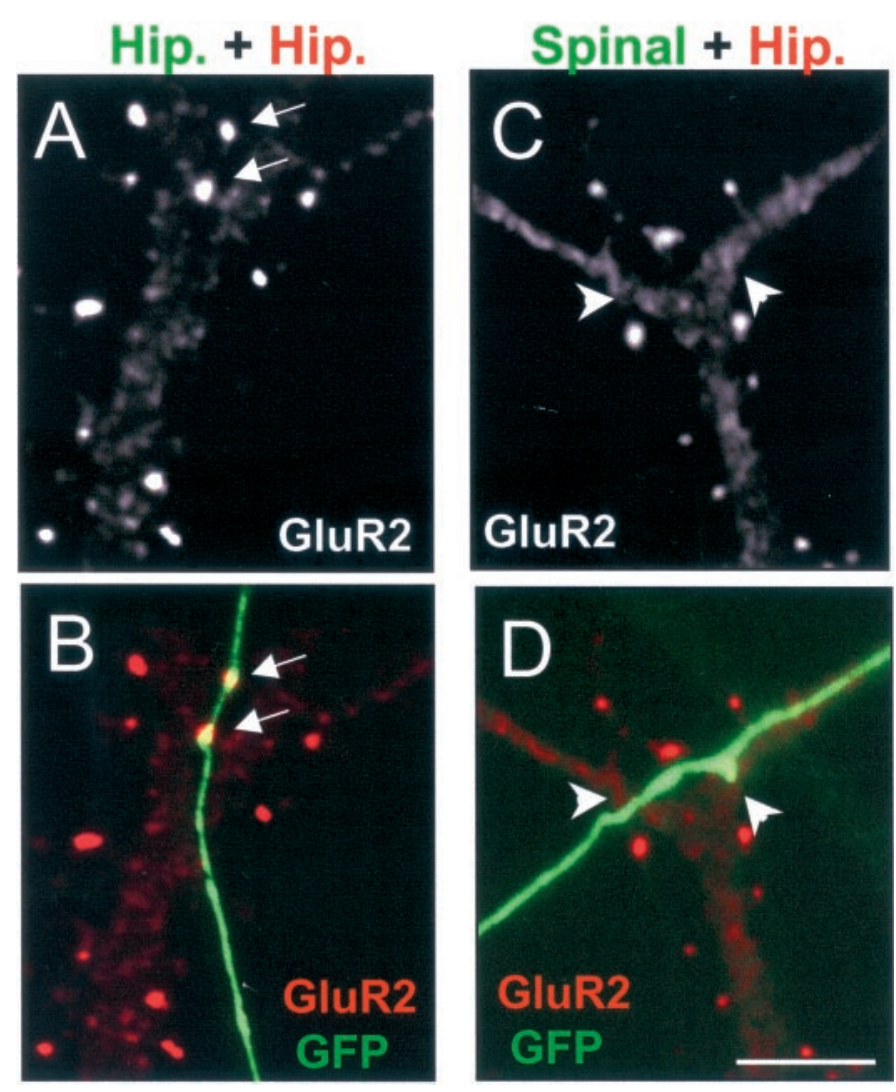

Figure 2. Differing capabilities of spinal and hippocampal axons to cluster glutamate receptors. $A, B$, A transfected (GFP positive) hippocampal axon (Hip) contacts a spiny hippocampal pyramidal cell stained with GluR2 (red). Two GluR2-positive spines (arrows) are seen to colocalize with the transfected axon. $C, D$, A transfected spinal cord axon contacts another spiny hippocampal pyramidal neuron. In this case no spine or shaft (arrowheads) clusters of GluR2 are seen to colocalize with the axon. Scale bar, $5 \mu \mathrm{m}$.

When we examined contacts between spinal cord axons and hippocampal interneurons, defined by their dendritic shaft GluR2 clusters (Fig. 3A, $B$, Table 1), the incidence of postsynaptic GluR2 and NR1 clusters at the site of contact with the spinal axons was much higher (57 and 47\%, respectively). This latter number is similar to the rate of GluR2 clustering at sites of contact between spinal axons and spinal dendrites and only slightly lower than the ability of hippocampal axons to induce similar clusters on hippocampal interneurons (Table 1). The ability of spinal axons to induce clusters of NR1 as well as GluR2 on hippocampal interneurons was unexpected given the absence of NR1 clusters in cultured spinal neurons (see below). We interpret our finding to mean that spinal axons lack the ability (molecules) to induce the formation of dendritic spines with their associated glutamate receptor clusters despite their ability to cluster these same receptors on hippocampal interneurons. This could be attributable to either an absence of a putative spine-inducing molecule or an inability to localize it to sites of contact with spiny neurons.

\section{The ability of spinal and hippocampal axons to cluster NMDA-type glutamate receptors is restricted by the postsynaptic neuron}

To further investigate the ability of spinal and hippocampal axons to induce the formation of NR1 clusters, we added GFPtransfected hippocampal neurons to cultures of untransfected 


\begin{tabular}{|c|c|c|}
\hline Presynaptic-postsynaptic & GluR2 & NR1 \\
\hline \multicolumn{3}{|l|}{ Spinal-hippocampal $(n=4)$} \\
\hline Spiny & $24 \pm 5^{*}$ & $13 \pm 3$ \\
\hline Interneuron & $57 \pm 4$ & $47 \pm 6$ \\
\hline \multicolumn{3}{|c|}{ Motoneuron-hippocampal $(n=4)$} \\
\hline Spiny & $12 \pm 4$ & $12 \pm 6$ \\
\hline Interneuron & $15 \pm 4$ & $11 \pm 3$ \\
\hline \multicolumn{3}{|c|}{ Hippocampal-hippocampal $(n=4)$} \\
\hline Spiny & $55 \pm 6$ & $71 \pm 5$ \\
\hline Interneuron & $66 \pm 7$ & $60 \pm 6$ \\
\hline \multicolumn{3}{|c|}{ Hippocampal (NarpN)-hippocampal $(n=4)$} \\
\hline Spiny & $73 \pm 5^{* * *}$ & $67 \pm 8$ \\
\hline Interneuron & $37 \pm 5^{* *}$ & $32 \pm 4^{* *}$ \\
\hline Spinal-spinal $(n=3)$ & $48 \pm 7$ & \\
\hline Hippocampal-spinal $(n=3)$ & $59 \pm 3$ & \\
\hline
\end{tabular}

Hippocampal, spinal, and motoneuron axons were examined at sites of contact with the dendrites of spinal cord neurons, hippocampal interneurons, and hippocampal pyramidal neurons for overlapping clusters of GluR2 and NR1. All numbers represent the mean $\pm \mathrm{SD}$ of the means of the indicated number of transfections. ${ }^{*} p<$ 0.02 compared with NR1 and compared with motoneuron associated GluR2 clusters. $* * p<0.01$ compared with control hippocampal-hippocampal interneuron clusters. $* * * p<0.02$ compared with control hippocampal axons.

spinal neurons or to cultures of spinal neurons that had been previously transfected with the nuclear localizing maker EYFPNuc to positively identify them. We believed that this latter step was necessary in some cases to positively identify spinal neurons because the density of AMPA receptor clusters on mature cultured spinal neurons approaches that of the added unlabeled, immature hippocampal interneurons. When assayed in this manner, axons from hippocampal neurons showed no ability to cluster NMDA receptors on spinal cord neurons, even those transfected with EYFP-Nuc (Fig. 3E-G, Table 1), compared with their ability to cluster AMPA receptors on those same neurons (Fig. 3C,D, Table 1) or compared with their ability to cluster NMDA receptors on hippocampal interneurons or pyramidal cells.

This lack of NR1 clustering on spinal dendrites when contacted by either a spinal or hippocampal axon is to be contrasted with the ease of such clustering when the same axons contact hippocampal interneurons (see above). The discrepancy is unlikely to be caused by a lack of expression of the NR1 subunit in cultured spinal neurons, because immunoblots of cultured spinal neurons show robust expression of NR1 in total or biotinylated (surface) fractions (Fig. 3H,I). This observation is in keeping with our previous work (O'Brien et al., 1997) in which we demonstrated robust NMDA chemosensitivity in cultured spinal neurons of a similar age, but no synaptic NR1 aggregation. We interpret our results as suggesting that postsynaptic spinal dendrites lack the ability to respond to an appropriate cue present on the axons of spinal and hippocampal axons. Whether this is attributable to the presence or absence of a specific NMDA receptor subunit or to the absence of an aggregating molecule such as PSD-95 is the subject of ongoing investigation.

\section{Differential axonal Narp accumulation}

Excitatory synapses in cultured spinal neurons are fairly homogenous, occurring on the dendritic shafts of the postsynaptic neuron. In another publication (O'Brien et al., 2002) we provide strong evidence that release of the AMPA receptor-aggregating molecule Narp by presynaptic axons facilitates the postsynaptic aggregation of AMPA-type glutamate receptors at these synapses. Consistent with this proposed model is the fact that Narp is found at most excitatory shaft synapses in cultured spinal neurons (O'Brien et al., 1999). In contrast, as mentioned above, cultured hippocampal neurons are composed of a mixture of cells with excitatory synapses that occur on dendritic spines or shafts in a mutually exclusive fashion. We have previously described the immunohistochemical distribution of endogenous Narp in cultured hippocampal neurons (O'Brien et al., 1999), showing that Narp colocalized with the majority of AMPA receptor clusters on the dendritic shafts of hippocampal interneurons but not with AMPA receptor clusters on the spines of hippocampal pyramidal cells. Because the axons of hippocampal pyramidal neurons can form excitatory synapses on both interneurons and other pyramidal cells (Aaron and Dichter 2001), this suggests the possibility that these axons can vary the secretion or accumulation of Narp at developing excitatory synapses, depending on the nature of the postsynaptic cell. To investigate this, hippocampal neurons were transfected with mycNarp along with a small amount of a GFPexpressing plasmid. After replating onto mature cultures of hippocampal neurons and further growth for $4 \mathrm{~d}$, the transfected Narp construct was identified on the surface of transfected cells by live staining with a rabbit anti-myc antibody.

As shown in Figure $4 A-C$, when axons from transfected hippocampal neurons contacted a hippocampal interneuron with its shaft clusters of AMPA receptors, the majority of contacts (47 of 73) had associated surface staining for mycNarp. The number of interneuron contacts associated with surface mycNarp staining was even higher when the hippocampal axon was associated with a cluster of GluR2 on the interneuron dendrite (38 of 44). In contrast, when axons from transfected hippocampal neurons induced clusters of GluR2 or NR1 on the spines of hippocampal pyramidal cells, extracellular mycNarp was either not present ( 83 of 107 contacts) or present in small aggregates that did not colocalize with the spine or shaft receptor cluster (18 of 107 contacts) (Fig. 4D-F). This observation implies either a failure of Narp secretion at spine synapses or a lack of local retention.

To examine whether mycNarp could accumulate differentially at spine and shaft synapses induced by individual axons, we identified single axons that could be unambiguously followed from a GluR2-associated contact with an interneuron to a GluR2associated contact with a spiny pyramidal cell. A total of 27 axons satisfied these criteria. Twenty-two of 27 interneuron contacts had overlapping surface mycNarp/GluR2 clusters (such as shown in Fig. $4 A-C$ ). Only 4 of the same 27 axons had any surface mycNarp staining near sites of contact with GluR2-containing pyramidal cell spines, 3 of which, as shown in Figure $4 D-F$, did not directly overlap with the spine. These observations suggest that the differential secretion/accumulation of mycNarp at spine and shaft synapses is a property of individual axons and not related to a difference in the types of axons that form synapses on interneurons or pyramidal cells.

\section{Dominant negative Narp mutants}

Given the differential accumulation of Narp at spine and shaft synapses in cultured hippocampal neurons, we postulated that Narp mutations which interfere with the secretion of endogenous Narp by cultured neurons should only affect the formation of glutamate receptor clusters on the dendrites of hippocampal interneurons but not on the spines of pyramidal cells. To answer this question we used the recently described dominant negative Narp mutant NarpN, a secretion-deficient, C-terminal truncation 

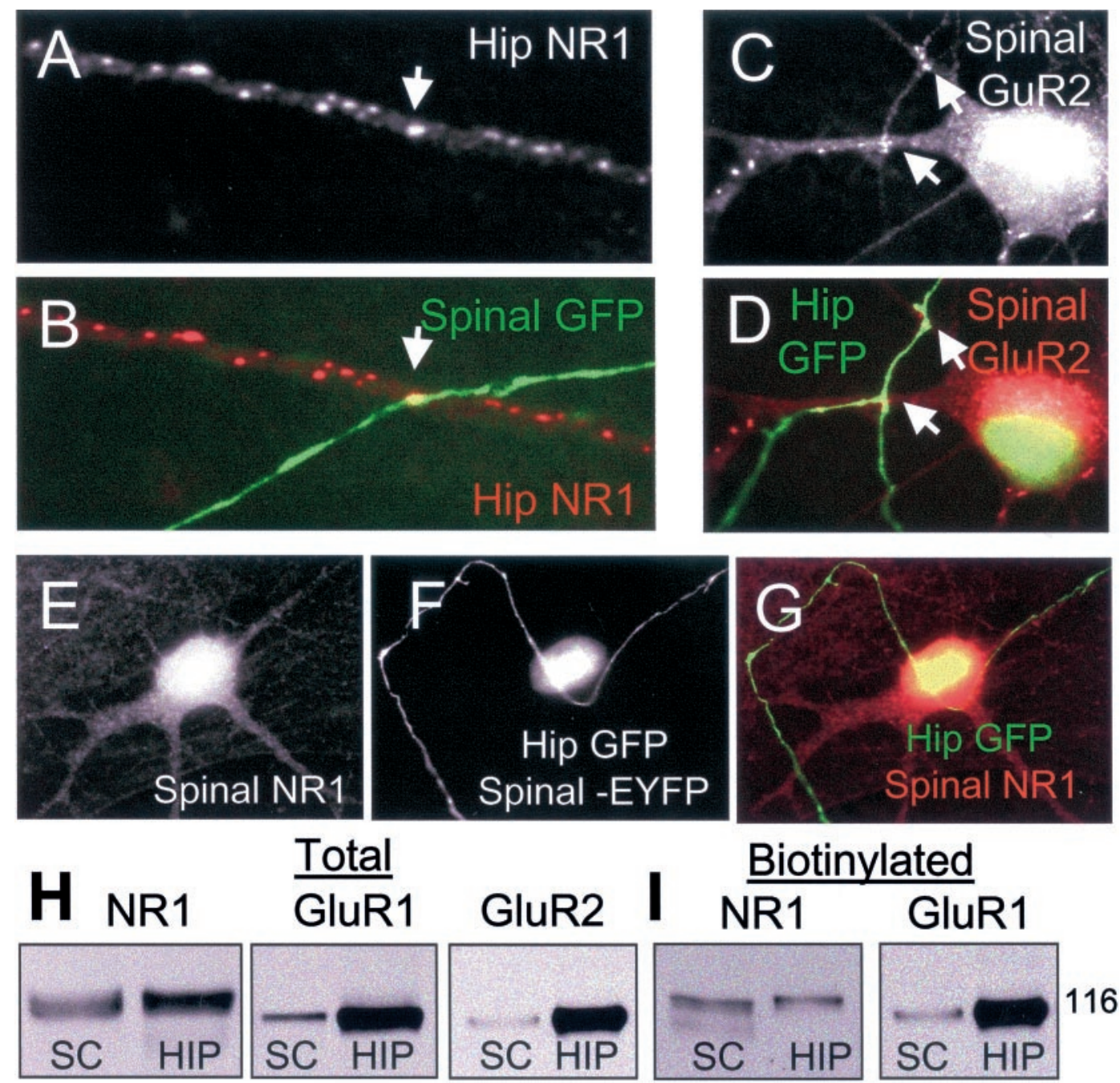

Biotinylated
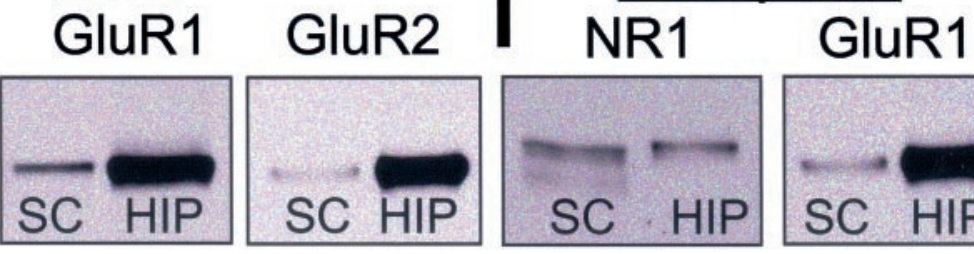

Figure 3. NMDA receptor aggregation is determined by the postsynaptic cell. $A, B$, A GFP-positive spinal axon contacts a hippocampal interneuron and is associated with a cluster of NR1. $C, D$, A GFP-positive hippocampal axon contacts a spinal neuron and is associated with several clusters of GluR2 (arrows). E-G, Another hippocampal axon contacts a spinal neuron and is not associated with clustered NR1. The spinal neuron is positively identified by the nuclear EYFP staining. H, I, Total and surface (biotinylated) NR1, GluR1, and GluR2 (total only) are shown from day 14 in vitro cultures of hippocampal and spinal neurons, demonstrating that the surface NR1 expression in spinal $(S C)$ and hippocampal cultures (HIP) is nearly equivalent, especially by comparison with GluR1 and GluR2.

mutant of Narp, that binds endogenous cellular Narp and prevents its secretion (O'Brien et al., 2002). In cultured spinal neurons, NarpN-transfected axons show a significantly diminished ability to cluster AMPA receptors at excitatory synapses.

Following the usual protocol, NarpN or control plasmid was transfected into hippocampal neurons on day 4 in vitro, and the transfected cells were then added to D10 hippocampal neurons. A small amount of a GFP-expressing plasmid was included to allow visualization of transfected axons. A blinded assay for the receptor-aggregating ability of transfected axons was performed, examining both interneuron and pyramidal cell dendritic contacts. As shown in Table 1, NarpN caused a significant decrease in the ability of hippocampal axons to cluster AMPA-type glutamate receptors on the shafts of hippocampal interneurons. In contrast, NarpN-transfected hippocampal axons showed an increased ability to cluster AMPA-type glutamate receptors on dendritic spines $(p<0.02)$. The rate of NMDA receptor aggregation at contacts between NarpN-transfected axons and untransfected dendrites was also significantly decreased, again only on the dendrites of hippocampal interneurons. NarpN had no effect on NR1 accumulation at spiny synapses. NarpN-transfected axons showed no change in the percentage of dendritic shaft contacts associated with GABA receptor clusters compared with controls (control, $25 \pm 5 \% ; n=4$ transfections; NarpN, $21 \pm 3 \%$; $n=4)$. We attempted to evaluate the potential role of postsynaptic NarpN expression on excitatory synapse formation in hippocampal cultures but found little expression of this construct $10 \mathrm{~d}$ after transfections. Possible explanations for this include a diminished expression of NarpN with time in cultured hippocampal neurons or a loss of the expressing neurons.

\section{The direct effect of exogenously applied Narp on glutamate receptor aggregation in hippocampal neurons}

The fact that NarpN caused a decrease in NR1 accumulation at excitatory synapses on hippocampal interneurons was surprising given the previously demonstrated lack of interaction between Narp and NMDA receptors (O'Brien et al., 1999). To examine 
Figure 4. Hippocampal axons localize mycNarp exclusively at interneuron synapses. $A-C$, A hippocampal axon from a neuron transfected with GFP and mycNarp contacts an interneuron. A cluster of surface mycNarp (green) is seen to colocalize with a GluR2 cluster (red) (C). $D-F$, Another transfected hippocampal axon contacts a spiny pyramidal cell where it colocalizes with two GluR2 clusters ( $D, E$, arrows). Two small clusters of mycNarp (green) appear along the axon $(F)$ but do not colocalize with the clustered spiny GluR2 staining.
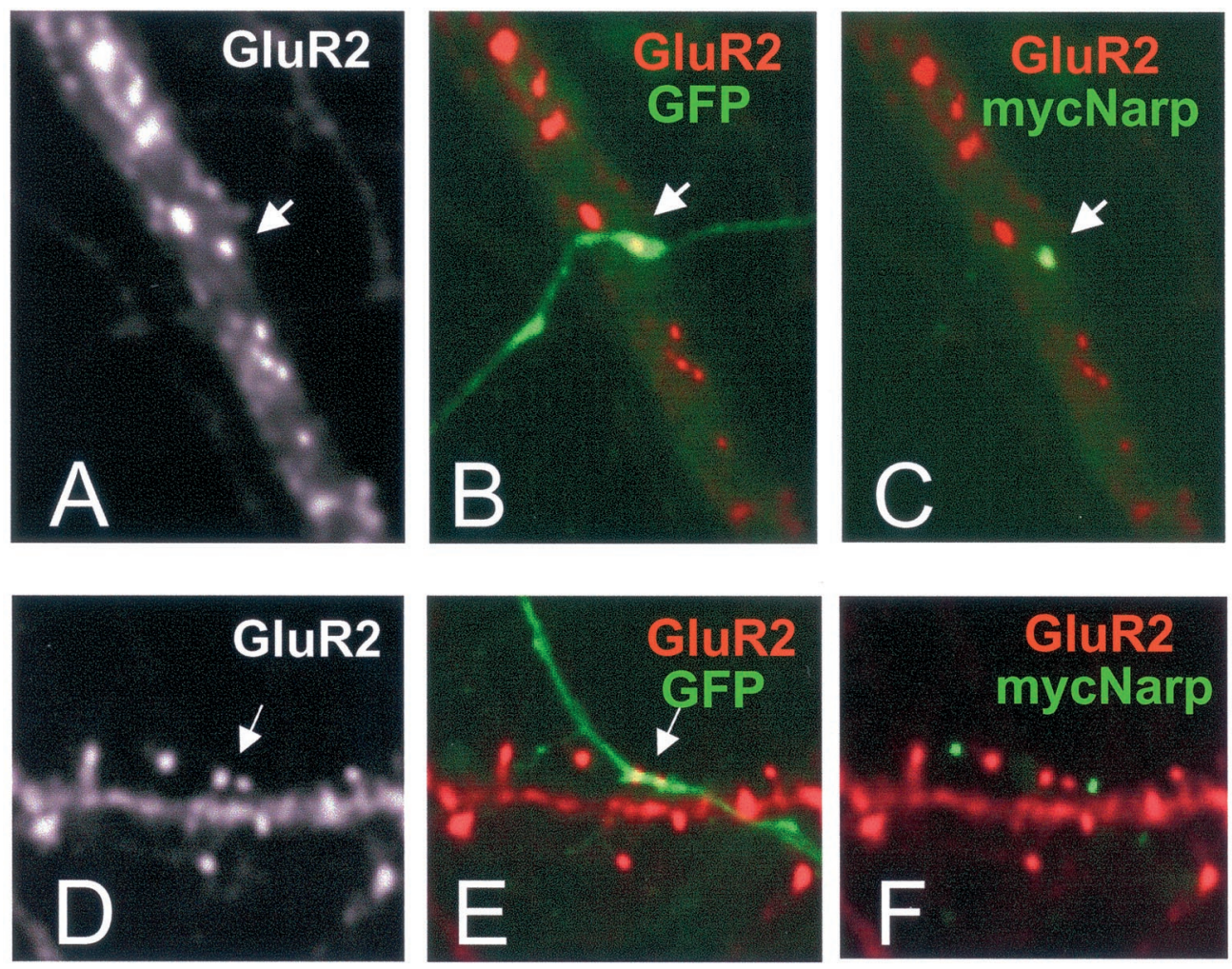

this more carefully, we transfected HEK 293 cells with mycNarp and added them to cultures of hippocampal and spinal neurons. This method of adding exogenous Narp is necessary because of the lack of binding or bioactivity of soluble Narp. When a Narptransfected 293 cell was observed to contact a spiny pyramidal cell (Fig. 5A-F), robust GluR1 and GluR2 accumulation was noted at sites of contact between Narp aggregates on 293 cells and the dendrites of the pyramidal cell. In contrast, NR1 was not aggregated at these contacts (Fig. 5G,H). Surprisingly, when mycNarptransfected 293 cells contacted a hippocampal interneuron, both GluR2 and NR1 were accumulated at sites of contact (Fig. $6 A-F)$. The accumulation of NR1 on interneurons appeared to be causally related to the presence of Narp, because these contacts were devoid of presynaptic synaptophysin staining (Fig. 6E). The ability of exogenous mycNarp to aggregate NR1 on hippocampal interneurons was independent of ongoing synaptic activity, because the presence or absence of CNQX $(10 \mu \mathrm{m})$ and APV $(0.5 \mathrm{~mm})$ had no effect on the ability of mycNarp to aggregate NR1. The ability of Narp to cluster NMDA-type glutamate receptors was restricted to hippocampal interneurons, because Narp did not cluster NMDA receptors on spinal neurons (Fig. $7 A, B$ ) or on hippocampal pyramidal neurons (Fig. $5 G, H$ ). Moreover, as reported previously, in heterologously transfected HEK 293 cells, Narp did not result in NMDA receptor aggregation no matter which combination of AMPA and NMDA receptor subunits was cotransfected with Narp (Fig. $7 C-E$ ).

Finally, in an attempt to identify other potential spineorganizing molecules, we examined contacts between hippocampal neurons (spiny and aspiny) and 293 cells transfected with three other proposed presynaptic spine-organizing molecules, neurexin 1B, ephrin A5, and ephrin B1. All constructs were epitope tagged and surface expressed. We saw no colocalization of postsynaptic NR1 or GluR2 with surface clusters of any of the three molecules when the 293 cell expressing them came in contact with a hippocampal pyramidal cell or interneuron.

\section{DISCUSSION}

\section{The differing capacities of spinal and hippocampal axons to aggregate glutamate receptors}

Our current work supports the notion that at least two distinct molecular mechanisms exist to cluster glutamate receptors at excitatory synapses in cultured spinal and hippocampal neurons. The first is a Narp-dependent system that appears to be dominant in spinal cord cultures and is sensitive to perturbations in the release of Narp. This Narp-based system also appears to be operative in hippocampal cultures in a more restricted pattern. Narp-expressing axons from spinal neurons are capable of clustering AMPA receptors on the dendrites of hippocampal interneurons and do so at a rate similar to their ability to cluster AMPA receptors in other spinal neurons. Hippocampal axons are also capable of clustering AMPA receptors on spinal neurons and hippocampal interneurons, with the latter process being sensitive to the dominant negative Narp mutant NarpN. Although the simplest explanation for these observations is that Narp is the dominant molecule in aggregating glutamate receptors on dendritic shafts, the possibility exists that Narp simply modulates the release of another key molecule. The fact that the dominant negative Narp mutant NarpN had only an incomplete effect in decreasing glutamate receptor clustering on the shafts of hippocampal interneurons could have several explanations. First, additional molecules may exist. Second, the effect of NarpN on endogenous Narp secretion may be incomplete. Third, as in spinal neurons, postsynaptic Narp, contributed by the interneuron itself, may help compensate for the loss of presynaptic Narp (O’Brien et al., 2002).

A second mechanism for clustering glutamate receptors at 

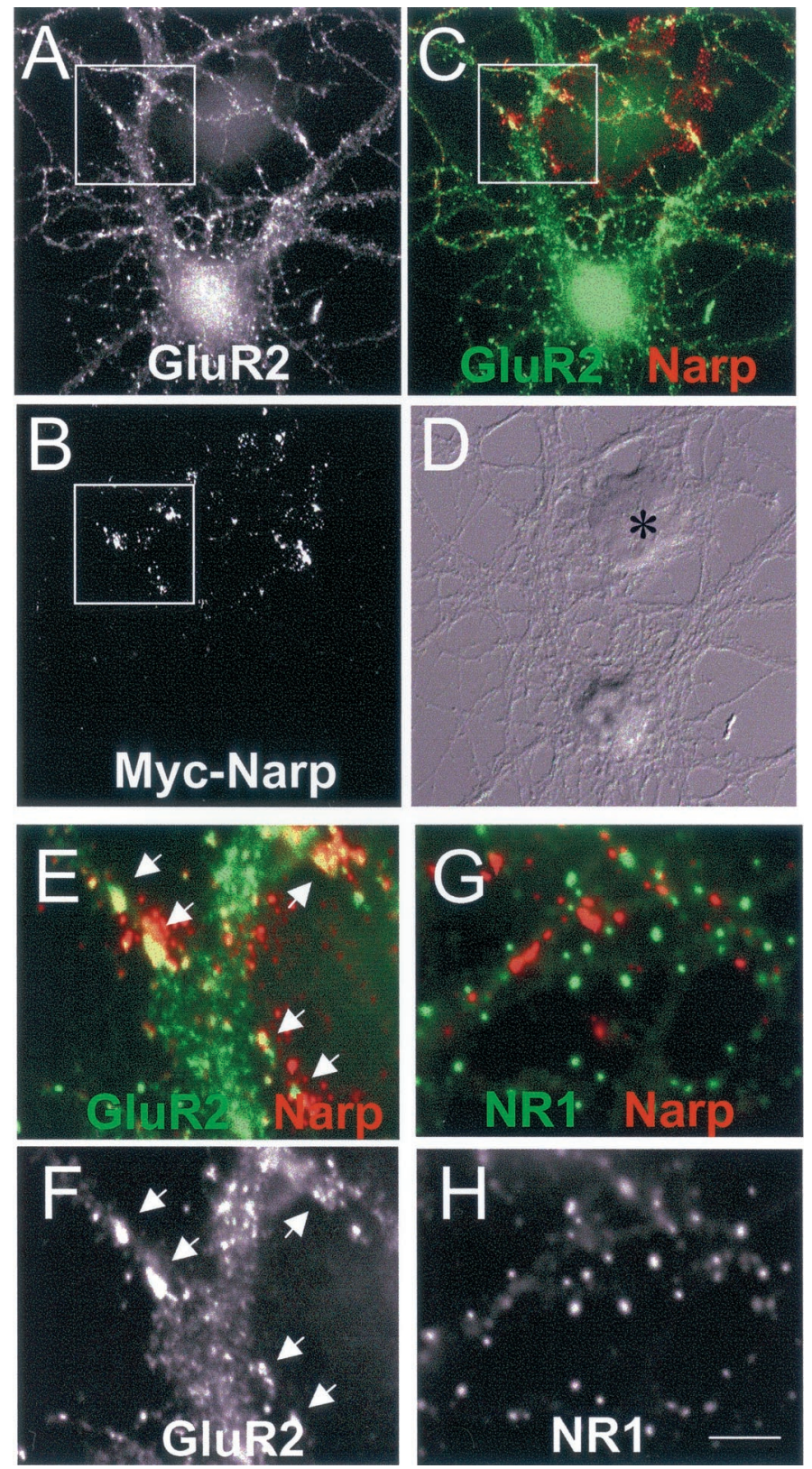

Figure 5. Narp clusters GluR1 but not NR1 on hippocampal pyramidal neurons. $A-F$, A mycNarp-transfected 293 cell $(B$, asterisk in $D)$ contacts a GluR1-positive pyramidal neuron $(A)$. $C$, Sites of overlap between mycNarp and GluR1 are seen ( yellow). Magnified views of the boxed areas indicated in $A$ and $C$ are shown in $F$ and $E$, respectively. The colocalizing clusters of mycNarp and GluR1 are indicated by arrows. $G, H$, Another 293 cell transfected with mycNarp showed no colocalization of NR1 immmunostaining ( green) with mycNarp (red).

excitatory synapses is evidenced at the spiny synapses of cultured hippocampal pyramidal cells. The ability to induce spine formation on mature hippocampal dendrites with their associated AMPA and NMDA receptor clusters is present in hippocampal axons within a few days after replating onto mature hippocampal neurons. In contrast, spinal axons do not have any capacity to induce clusters of NMDA-type glutamate receptors on hippocampal pyramidal cells and a greatly diminished capacity to cluster AMPA receptors on these neurons. The differential clustering capability for AMPA and NMDA receptors may represent some residual activity of the Narp present in spinal axons to cluster AMPA receptors. We favor this interpretation over the presence of an additional aggregating factor in spinal neurons because the complete lack of NMDA receptor clustering is consistent with the bioactivity of Narp (O'Brien et al., 1999). The fact that NarpN does not diminish, and in fact increases, the ability of hippocampal axons to induce clusters of glutamate receptors on dendritic spines further suggests that the clustering of glutamate receptors on the spines of hippocampal pyramidal cells is a process that does not use Narp. Indeed, the increase in spiny GluR2 clusters associated with NarpN-transfected axons may imply that the two processes are coupled in a compensatory manner.

It should be noted that the lack of induction of any type of excitatory synapse (spine or shaft) on hippocampal pyramidal cells by spinal axons may indicate a lack of responsiveness of this class of neurons to factors present on spinal axons, caused by the lack of either a specific receptor or an interacting adhesion molecule. An additional caveat is that our assay measures the colocalization of transfected axons with postsynaptic clusters of glutamate receptors. Only time-lapse recordings will definitively prove that these are inductive phenomena.

\section{Transport and accumulation of Narp at synapses}

In our previous study (O'Brien et al., 1999) we showed that Narp expressed in spinal neurons is selectively transported down the axons of excitatory neurons, where it accumulates at excitatory synapses. In the present paper we demonstrate that Narp can be selectively accumulated at a specific type of excitatory synapse, those on dendritic shafts, even when the axon that secretes it is involved in the formation of excitatory synapses on both spine and shafts. This remarkable specificity could come through selective secretion or selective immobilization at the site of secretion. The selective accumulation of Narp at contacts with interneurons (as opposed to those with spiny neurons) likely explains the diminished capacity of spinal axons to cluster AMPA receptors on pyramidal neurons, given the ability of exogenous Narp to do so. One other example of selective presynaptic accumulation by a single class of axons was reported by Shigemoto et al. (1996), who showed that the presence of the presynaptic metabotropic receptor mGluR7 varied at hippocampal synapses depending on whether the postsynaptic target was a pyramidal cell or an interneuron. Rubio and Wenthold (1997), Landsend et al. (1997), and Nusser et al. (1998) have shown differential sorting of postsynaptic glutamate receptors in individual neurons. The identification of a receptor for Narp is a crucial next step in understanding its mechanism of action. In addition, the identification of mutations that disrupt the selective localization of Narp by hippocampal axons will also be important.

\section{The role of the postsynaptic cell in determining synaptic NMDA receptor aggregation}

It was a surprise to find that spinal axons were capable of clustering NMDA-type glutamate receptors on hippocampal interneurons, because NMDA-type glutamate receptors are not normally aggregated at excitatory synapses in cultured spinal neurons. Moreover, evidence from hippocampal neurons transfected with NarpN, a dominant negative mutant that interferes with the secretion of endogenous Narp, suggests that Narp is directly related to the synaptic clustering of NMDA receptors in these neurons. This hypothesis is further supported by the observation that exogenously applied Narp results in the aggrega- 


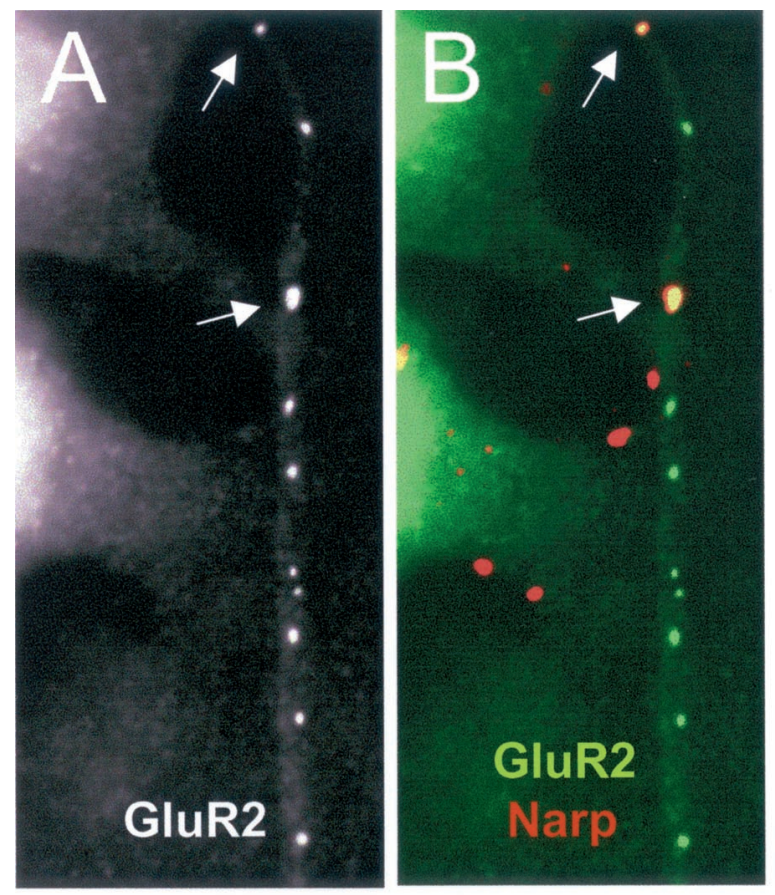

Figure 6. Narp clusters NR1 and GluR2 on hippocampal interneurons. $A, B$, Surface mycNarp from a transfected 293 cell $($ red $)$ is seen to colocalize with two clusters of GluR2 (green) on a contacted interneuron (arrows). $C-E$, Another interneuron, this time stained with an antibody to NR1, is contacted by another mycNarp-secreting 293 cell. Multiple sites of mycNarp (red) and NR1 ( green) overlap are seen $(C$, $D$, asterisk). In $E$, the sites of mycNarp-NR1 overlap are devoid of presynaptic synaptophysin immunostaining (red).
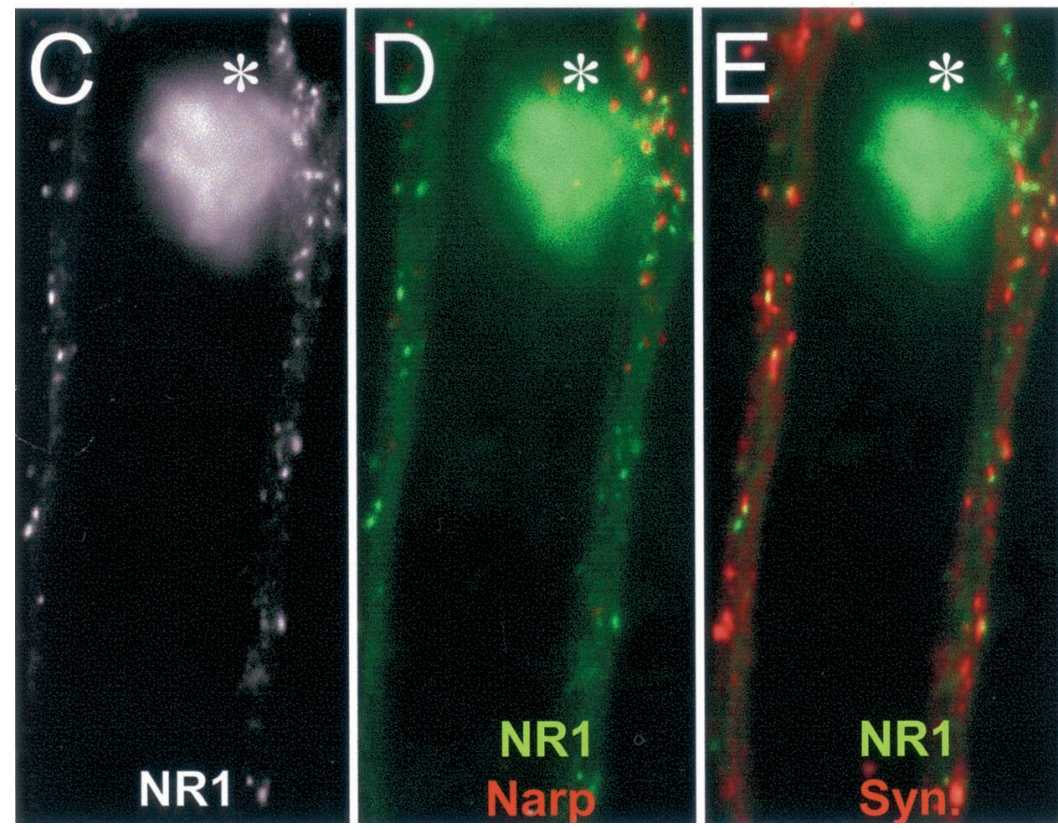

tion of AMPA and NMDA receptors on hippocampal interneurons. That Narp is sufficient for AMPA and NMDA receptor aggregation at excitatory synapses on hippocampal interneurons implies that an additional, NMDA receptor-specific, presynaptic aggregating molecule is not necessary.

Because we have never been able to demonstrate a direct interaction between Narp and NMDA receptors in 293 cells, we suspect that the aggregation of NMDA receptors is a secondary result of the AMPA receptor aggregation. Possible molecular explanations for why interneurons are capable of coupling AMPA and NMDA receptor aggregation whereas spinal and pyramidal neurons are not include the presence or absence of specific NMDA receptor subunits that mediate this interaction (other than NR1), the presence or absence of specific cytoplasmic coupling molecules, or an additional receptor for Narp on the surface of interneurons that mediates Narp-NMDA receptor interactions. The uncoupling of NMDA- and AMPA-type receptors in hippocampal pyramidal neurons has important physiologic implications (see below). The ability to directly transfect cultured spinal neurons with exogenous DNA should facilitate the identification of candidate molecules capable of mediating the interaction between NMDA- and AMPA-type glutamate receptors.

\section{The molecular differences between excitatory synapses on dendritic spines and shafts}

The proposed differences in the expression and bioactivity of Narp at spine and shaft synapses are not the first molecular differences noted between these two types of synapses. Although they have not been studied in great detail, excitatory dendritic shaft synapses are known to differ from spine synapses in some of 


\section{Spinal Neurons}

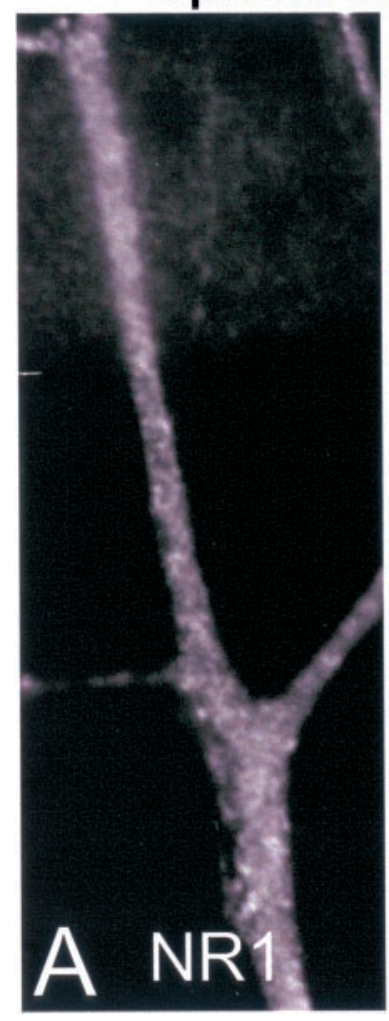

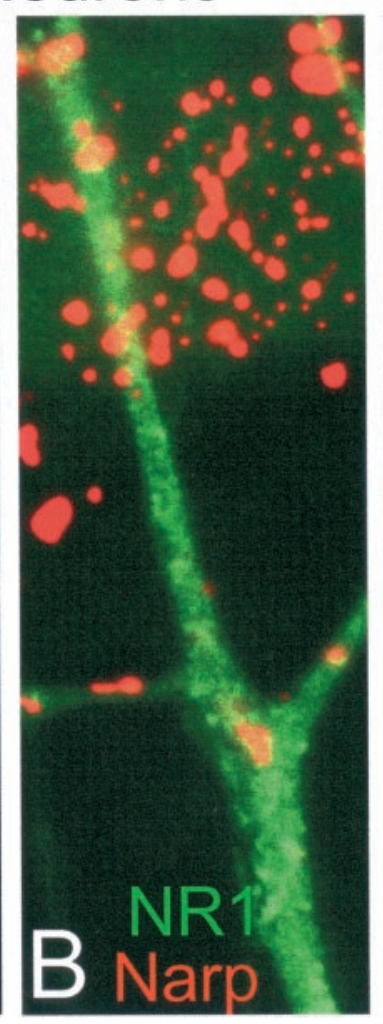

\section{HEK 293 Cells}
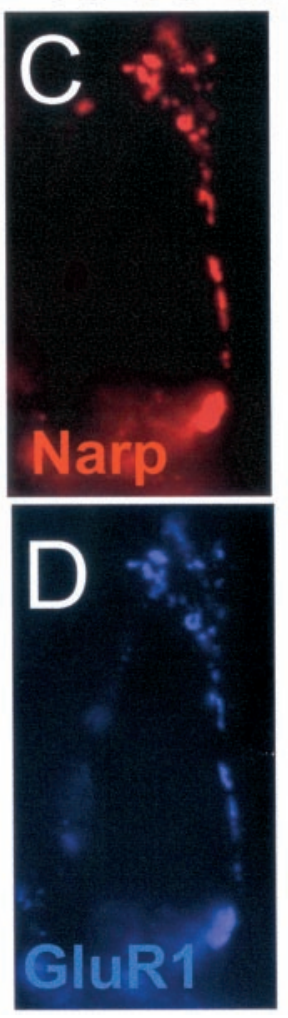

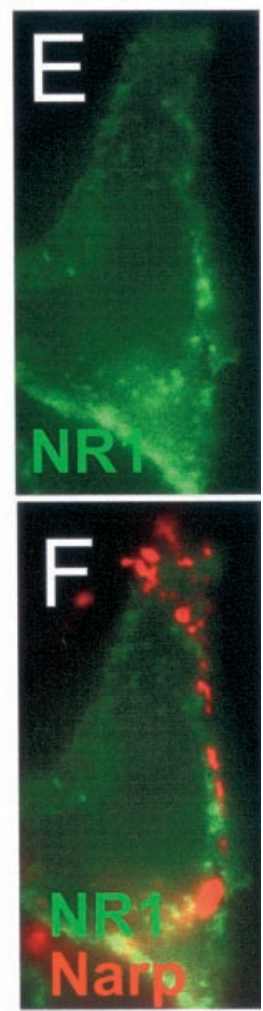

Figure 7. Narp does not cluster NR1 in spinal neurons or HEK 293 cells. $A, B$, The dendrite of a spinal neuron immunostained with an antibody to NR1 is contacted by a mycNarp-expressing 293 cell $(B, r e d)$. No coclustering of NR1 is seen. $C-F$, A 293 cell expressing Narp (red), HA-tagged GluR1 (blue), NR2A (untagged), and myc-tagged NR1 (green) is seen to colocalize GluR1 and Narp $(C, D)$ but not NR1 and Narp $(F)$. the molecular components present. Examples include SynGAP, citron, and bundled actin filaments (Allison et al., 1998; Zhang et al., 1999). Even NMDA- and AMPA-type glutamate receptor subunits are themselves expressed differentially at these two types of excitatory synapses (O'Brien et al., 1997; Allison et al., 1998; Gomperts et al., 1998; Lissin at al., 1998; Rao et al., 1998; Liao et al., 1999). Functionally, excitatory synapses on spines and shafts also differ. Dendritic shaft synapses in hippocampal interneurons have been resistant to LTP induction (McBain et al., 1999) and undergo homeostatic scaling in a manner different from pyramidal cells (Rutherford et al., 1998).

Although Narp appears to be an excellent fit for a mediator of AMPA-type glutamate receptor aggregation on dendritic shafts in cultured hippocampal neurons, it is not a good fit at excitatory synapses on dendritic spines. The absence of Narp at dendritic spines in cultured hippocampal neurons initially suggested the presence of a "missing factor." In addition, the inability of exogenous Narp to cluster NMDA receptors on spiny hippocampal neurons also strongly argues against a role for Narp in these synapses. It must be recalled that in pyramidal neurons excitatory synapses are likely to go through an NMDA receptor-only phase, a phase crucial to synaptic plasticity (Lissin et al., 1998; Liao et al., 1999; Malinow et al., 2000). Given the bioactivity of exogenous Narp when in contact with hippocampal pyramidal cells, it would appear that Narp is not capable of mediating this phase. Although it is possible that Narp could facilitate the subsequent localization of AMPA-type receptors at spiny synapses, the failure of mycNarp to accumulate at these synapses would make this unlikely.

The identity of the molecules that regulate glutamate receptor accumulation at spine synapses is not clear, although both the neuroligins (Song et al., 1999) and ephyrins (Torres et al., 1998;
Gerlai, 2001) have been postulated to play a role. We have directly tested two member of the family of ephrin/Eph receptors: ephrin A5, which activates the EphA class of receptors, and ephrin B1, which activates the EphB class of receptors (Wilkinson 2001). Neither was observed to have any effect on postsynaptic receptor clustering. In addition, we also tested neurexin $1 \mathrm{~B}$, which activates the postsynaptic receptor neuroligin (Song et al., 1999; Rao et al., 2000). This also had no observable effect. Although serving as controls for the effect of Narp, these experiments also direct attention away from these particular molecules, at least in isolation. Using our in vitro system to directly test other candidate molecules will remain an important project.

\section{REFERENCES}

Aaron GB, Dichter MA (2001) Excitatory synapses from CA3 pyramidal cells onto neighboring pyramidal cells differ from those onto inhibitory interneurons. Synapse 42:199-202.

Acsady L, Kamondi A, Sik A, Freund T, Buzsaki G (1998) GABAergic cells are the major postsynaptic targets of mossy fibers in the rat hippocampus. J Neurosci 18:3386-3403.

Allison DW, Gelfand VI, Spector I, Craig AM (1998) Role of actin in anchoring postsynaptic receptors in cultured hippocampal neurons: differential attachment of NMDA versus AMPA receptors. J Neurosci 18:2423-2436.

Banker GA, Cowan WM (1979) Further observations on hippocampal neurons in dispersed cell culture. J Comp Neurol 187:469-493.

Camu W, Henderson CE (1992) Purification of embryonic rat motoneurons by panning on a monoclonal antibody to the low-affinity NGF receptor. J Neurosci Methods 44:59-70.

Craig AM, Blackstone CD, Huganir RL, Banker G (1994) Selective clustering of glutamate and gamma-aminobutyric acid receptors opposite terminals releasing the corresponding neurotransmitters. Proc Natl Acad Sci USA 91:12373-12377.

Dong H, O'Brien RJ, Fung ET, Lanahan AA, Worley PF, Huganir RL (1997) GRIP: a synaptic PDZ domain-containing protein that interacts with AMPA receptors. Nature 386:279-284.

Gerlai R (2001) Eph receptors and neural plasticity. Nat Rev Neurosci 2:205-209. 
Gomperts SN, Rao A, Craig AM, Malenka RC, Nicoll RA (1998) Postsynaptically silent synapses in single neuron cultures. Neuron 21:1443-1451

Jakowec MW, Fox AJ, Martin LJ, Kalb RG (1995) Quantitative and qualitative changes in AMPA receptor expression during spinal cord development. Neuroscience 67:893-907.

Landsend AS, Amiry-Moghaddam M, Matsubara A, Bergersen L, Usami S, Wenthold RJ, Ottersen OP (1997) Differential localization of $\delta$ glutamate receptors in the rat cerebellum: coexpression with AMPA receptors in parallel fiber-spine synapses and absence from climbing fiber-spine synapses. J Neurosci 17:834-842.

Liao D, Zhang X, O’Brien R, Ehlers M, Huganir R (1999) Regulation of morphological postsynaptic silent synapses in developing hippocampal neurons. Nature Neuroscience 2:37-43.

Lissin DV, Gomperts SN, Carroll RC, Christine CW, Kalman D, Kitamura M, Hardy S, Nicoll RA, Malenka RC, von Zastrow M (1998) Activity differentially regulates the surface expression of synaptic AMPA and NMDA glutamate receptors. Proc Natl Acad Sci USA 95:7097-7102.

Malinow R, Mainen ZF, Hayashi Y (2000) LTP mechanisms: from silence to four-lane traffic. Curr Opin Neurobiol 10:352-357.

Mammen AL, Huganir RL, O’Brien RJ (1997) Redistribution and stabilization of cell surface glutamate receptors during synapse formation. J Neurosci 17:7351-7358.

McBain CJ, Freund TF, Mody I (1999) Glutamatergic synapses onto hippocampal interneurons: precision timing without lasting plasticity. Trends Neurosci 22:228-235.

Nusser Z, Lujan R, Laube G, Roberts JD, Molnar E, Somogyi P (1998) Cell type and pathway dependence of synaptic AMPA receptor number and variability in the hippocampus. Neuron 21:545-559.

O'Brien RJ, Mammen AL, Blackshaw S, Ehlers MD, Rothstein JD, Huganir RL (1997) The development of excitatory synapses in cultured spinal neurons. J Neurosci 17:7339-7350.
O’Brien RJ, Xu D, Petralia RS, Steward O, Huganir RL, Worley P (1999) Synaptic clustering of AMPA receptors by the extracellular immediateearly gene product Narp. Neuron 23:309-323.

O'Brien RJ, Xu D, Mi R, Hopf C, Tang X, Worley P (2002) The role of the neuronal pentraxin Narp in the formation of excitatory synapse in cultured spinal neurons. J Neurosci 22:4487-4498.

Rao A, Kim E, Sheng M, Craig AM (1998) Heterogeneity in the molecular composition of excitatory postsynaptic sites during development of hippocampal neurons in culture. J Neurosci 18:1217-1229.

Rao A, Harms KJ, Craig AM (2000) Neuroligation: building synapses around the neurexin-neuroligin link. Nat Neurosci 3:747-749.

Rubio ME, Wenthold RJ (1997) Glutamate receptors are selectively targeted to postsynaptic sites in neurons. Neuron 18:939-950.

Rutherford LC, Nelson SB, Turrigiano GG (1998) BDNF has opposite effects on the quantal amplitude of pyramidal neuron and interneuron excitatory synapses. Neuron 21:521-530.

Sheperd GM (1998) The synaptic organization of the brain, Ed 4. New York: Oxford UP.

Shigemoto R, Kulik A, Roberts JD, Ohishi H, Nusser Z, Kaneko T, Somogyi P (1996) Target-cell-specific concentration of a metabotropic glutamate receptor in the presynaptic active zone. Nature 381:523-525.

Song JY, Ichtchenko K, Sudhof TC, Brose N (1999) Neuroligin 1 is a postsynaptic cell-adhesion molecule of excitatory synapses. Proc Nat Acad Sci USA 96:1100-1105.

Torres R, Firestein BL, Dong H, Staudinger J, Olson EN, Huganir RL Bredt DS, Gale NW, Yancopoulos GD (1998) PDZ proteins bind, cluster, and synaptically colocalize with Eph receptors and their ephrin ligands. Neuron 21:1453-1463. Wilkinson DG (2001) Multiple roles of $\mathrm{EPH}$ receptors and ephrins in neural development. Nat Rev Neurosci 2:155-164.

Zhang W, Vazquez L, Apperson M, Kennedy MB (1999) Citron binds to PSD-95 at glutamatergic synapses on inhibitory neurons in the hippocampus. J Neurosci 19:96-108. 